\title{
Perceptions of genetic research in three rural Appalachian Ohio communities
}

\author{
Amy N. Fullenkamp • Erin N. Haynes • Lisa Meloncon • Paul Succop • Daniel W. Nebert
}

Received: 14 May 2012 / Accepted: 25 July 2012 /Published online: 5 August 2012

(C) Springer-Verlag 2012

\begin{abstract}
Appalachian Americans are an underserved population with increased risk for diseases having strong genetic and environmental precursors. The purpose of this study is to understand the thoughts and perceptions of genetic research of Appalachian Americans residing in eastern Ohio prior to conducting a genetic research study with this population. A genetic survey was developed and completed by 180 participants from Marietta, Cambridge and East Liverpool, Ohio. The majority of respondents were Caucasian women with a median age of 37.5 years. We found that participants had a high interest in participating in $80 \%$, allowing their children to participate in $78 \%$, and learning more about genetic research studies (90\%); moreover, they thought that genetic research studies are useful to society $(93 \%)$. When asked what information would be useful when deciding to participate in a genetic research study, the following were most important: how environmental pollutants affect their genes and their child's genes ( $84 \%$ ), types of biological specimens needed for genetic research studies $(75 \%)$ and who will have access to their samples (75\%). Of the $20 \%$ who responded that they were "unsure" about participating in a genetic research study, the leading reason was "I don't have enough information about genetic research to make a decision" (56\%). We also asked respondents to choose their preferred method for receiving genetic information, and the principal response was to read a brochure (40\%). Findings from this study will improve community education materials and
\end{abstract}

A. N. Fullenkamp $•$ E. N. Haynes $(\bowtie) \cdot$ P. Succop $\cdot$ D. W. Nebert Department of Environmental Health, College of Medicine, University of Cincinnati,

Cincinnati, USA

e-mail: Erin.Haynes@uc.edu

\section{Meloncon}

Department of English and Comparative Literature,

College of Arts and Sciences, University of Cincinnati,

Cincinnati, USA dissemination methods that are tailored for underserved populations engaged in genetic research.

\section{Introduction}

Complex diseases are considered multiplex phenotypes, i.e., traits that reflect the contribution of dozens or hundreds of genes plus epigenetic effects that include innumerable daily environmental insults. Such diseases, including diabetes, obesity, and heart disease are growing at an alarming rate: $11 \%$ of all Americans have diabetes, $12 \%$ heart disease, $34 \%$ of adults over 20 years of age and $20 \%$ of children aged 6-11 are obese (CDC 2012a, b). Therefore, appreciation of the complexities of the genome and the interplay between genes and the environment has grown logarithmically, subsequently spurring an increase in human genome sequencing technologies.

Advances in next-generation sequencing such as wholeexome and whole-genome sequencing technologies that can yield an individual's entire genetic make-up are becoming more affordable; thus, in the near future, these technologies may provide a more realistic option for improving patient diagnosis and treatment (von Bubnoff 2008; Bick et al. 2011). Additionally, metabolomics analyses in combination with genome-wide association studies are potentially providing new avenues for individualized drug therapy for a wide range of health problems (Suhre et al. 2011). These scientific advances coupled with the increased availability of direct-to-consumer personal genome testing (DTC-PGT) (Samuel et al. 2010) are allowing for easy accessibility to one's genetic information. However, even with all these technological and scientific advances becoming more integrated into our culture, many Americans lack an understanding of basic genetic concepts (Lanie et al. 2004). These current advances not only beg for increased awareness of 
genetics by the public but also afford new opportunities for research with susceptible or high-risk groups.

One such group is the rural Appalachians, a historically medically underserved group with higher mortality rates for all causes of death as compared with urban populations (Friedell et al. 1997; Elnicki et al. 1995; Halverson et al. 2004; Murray et al. 2005). Specifically, Appalachians are at an increased risk for diseases with strong genetic and environmental components - such as heart disease (Halverson et al. 2002; Barnett et al. 2002), cancer (Wingo et al. 2005), diabetes (Halverson et al. 2004), and obesity (CDC 2012a, b) - compared with other ethnic groups or those living in non-rural areas (Hurley et al. 2000). Appalachia is composed of 13 states and extends from New York to Mississippi (ARC 2008). The interaction between environmental exposures and genetics as a disease catalyst warrants further environmental genetic research, yet very few studies have included rural Appalachians in their research studies (Barnett et al. 2002; Wewers et al. 2000; Haynes et al. 2010; Hendryx et al. 2009; Steenland et al. 2009; Standridge et al. 2008). In order to develop appropriate communication about environmental genetic research with this population, it is essential to understand their thoughts and perceptions of genetic research and the role of environment. Thus, the purpose of this study was to assess the thoughts and perceptions about genetic research studies of Appalachian community members.

\section{Methods}

\section{Study population}

Persons from three rural, Appalachian Ohio communities were invited to participate in this genetic research questionnaire study, based on their participation in two research studies: Marietta Community Actively Researching Exposure Study (CARES) and the East Liverpool Pilot Study. Marietta CARES is a community-based participatory research study of children ages 7 to 9 years who have resided in Marietta or Cambridge, $\mathrm{OH}$ or the surrounding areas since birth. The research study is based on a community-academic partnership designed to determine if air pollution, particularly manganese exposure effects child neurobehavior [Haynes et al. 2011]. The research study is continuing to enroll participants and a sub study have been described elsewhere (Haynes et al. 2012). The East Liverpool Pilot Study was designed to determine the extent of metal exposure in children residing in East Liverpool and the surrounding area. Parents and/or legal guardians of all participating children signed a University of Cincinnati Institutional Review Board approved consent form and were invited to complete the genetic research questionnaire.
Development and distribution of questionnaire

A self-administered genetics research questionnaire was developed to gauge the target population: (1) their thoughts about the benefits of genetic research on society; (2) perceptions about the environment and its effects on health; (3) reasons for deciding to participate, or not participate, in a genetic research study; (4) interest in learning more about genetics and information that might be helpful in their decision-making process of participating in a genetic research study; (5) interest in participating in a genetic research study; (6) opinions about the best method for receiving information about participating in a genetic research study; and (7) preferences for how best to receive information on genetic research provided to the public. Basic demographics of the questionnaire participants (age, gender, level of education, and race) were also included.

The preliminary draft of the questionnaire was based on findings from four focus groups in Marietta, $\mathrm{OH}$ and Cambridge, $\mathrm{OH}$. The purpose of the focus groups was to determine a baseline of community members' knowledge about genetics and genetics research studies. Community members, environmental health experts, and communication experts from the University of Cincinnati reviewed the questionnaire to narrow the scope of the primary goal of the questionnaire. After this initial review, the questionnaire was piloted with ten residents of Steubenville, an eastern Ohio Appalachian community of similar socioeconomic status to the target population. The pilot of the questionnaire enabled us to re-write questions, combine and/or eliminate redundant questions, and ensure maximum readability and understanding of the questions' language and purpose.

The questionnaire was then mailed to every Marietta and Cambridge CARES participant currently enrolled in the ongoing study $(n=229)$, and was also provided to East Liverpool Pilot Study participants during their participation in the pilot study. Questions were answered by the legal guardian of the participating child about their thoughts on participation by both themselves and their children in a potential genetic research study. Information received from participants was assessed using multiple-choice statements with the response options: "Agree", "Don't Know", or "Disagree" (See Table 1) or "Important", "Somewhat Important", "Not Important" or "Not Sure". We also asked questions with "Yes", "No", or "Unsure" response options. Additionally, we asked questions with the option for choosing existing multiple-choice statements, as well as the opportunity for participants to fill in a statement in the "other" category.

Data management and analysis

All survey responses were double-entered into REDCap (Research Electronic Data Capture). REDCap is a secure, 
Table 1 Demographics of survey participants

\begin{tabular}{llll}
\hline & $n(\%)$ & & \\
\hline Age (ranges) & & Age (years) & \\
$25-34$ & $71(40 \%)$ & Mean & 37.5 \\
$35-44$ & $74(42 \%)$ & Median & 36 \\
$45-64$ & $32(18 \%)$ & Range & $26-61$ \\
Gender & & & \\
Females & $154(85 \%)$ & \\
Males & $26(14 \%)$ & \\
Race & & \\
Caucasian & $173(96 \%)$ & \\
African-American & $2(1 \%)$ & \\
American Indian & $1(<1 \%)$ & \\
Asian & $1(<1 \%)$ & \\
Other & $3(2 \%)$ & \\
Education level & & \\
8th grade & $3(2 \%)$ & \\
High school & $46(26 \%)$ & \\
Some college & $42(24 \%)$ & \\
Associates degree & $45(25 \%)$ & \\
Bachelor's degree & $26(15 \%)$ & \\
Master's degree & $13(7 \%)$ & \\
PhD & $4(2 \%)$ & \\
\hline
\end{tabular}

$n=177$

web-based application designed exclusively to support data capture for research studies (CCTST 2012). Incomplete or improperly answered questions were discarded, resulting in a varying numbers of respondents for each question. The demographics, number of participants, and their answers to each type of question were recorded and categorized. Also, the 'other' category of answers was also entered and categorized, based on similarities in responses. The percentages of responses for each question were calculated and reported as $n(\%)$. Contingency table analysis was performed using SAS PROC FREQ and significance was judged at $p<0.05$.

\section{Results}

Characteristics of the study population

Of the 229 questionnaires distributed in the Appalachian Ohio communities of Marietta, Cambridge, and East Liverpool, 180 (79 \%) participants responded (Table 1). The participant population was predominantly Caucasian (96\%) and female (86\%) with a median age of 37.5 years. The majority of participants reported an education level which ranged from a high school diploma (26\%), associate's degree (25\%), and bachelor's degree (15\%).
Approximately $24 \%$ of our study participants reported earning a bachelor's degree or higher. According to the 2010 US Census Bureau, our study participants reported higher educational attainment than reported by their respective county. For instance, in Marietta (Washington County) $16 \%$ have bachelor's degrees or higher, whereas Cambridge (Guernsey County) and East Liverpool (Columbiana County) reported having $11 \%$ and $12 \%$ bachelor's degrees or higher, respectively. Nationally, $28 \%$ reported earning a bachelor's degree or higher (US Census 2010).

Perceptions about genetic research and environmental health

To assess the participants' views on genetic research, we asked them a series of questions pertaining to genetic research studies and the usefulness of such studies in society (Table 2). Most participants agreed that genetic studies are good for society $(93 \%)$. The majority also agreed that genetic research studies: increase human lifespan $(81 \%)$, prevent disease $(88 \%)$, and are used to treat disease $(82 \%)$. However, a large proportion of participants responded that they needed more information on the subject (44\%) or disagreed $(30 \%)$ that genetic discoveries are of immediate help to society. These findings show that this community regards genetic research highly; however, prior to the launch of a genetic research study with this population, there is a need for increased education on topics concerning the usefulness of genetic research studies.

We also wanted to know the participants' thoughts about how environmental exposures might affect human health (Table 2). Almost three fourths (74\%) of the participants agreed that environmental exposures affected their genes, whereas $41 \%$ responded that they needed more information on the subject; $4 \%$ disagreed. To determine the level of knowledge on "epigenetics", we asked two questions regarding cigarette smoking and its effects on the genes in subsequent generations. When asked if parental cigarette smoking affects their child's genes: $44 \%$ of the participants agreed, $46 \%$ needed more information, and $10 \%$ disagreed. When asked if grandparental smoking affects a grandchild's genes: $29 \%$ agreed, more than half (57\%) needed more information, and $14 \%$ disagreed. We also asked the participants whether they had ever heard of the term "epigenetics", and a large majority (90\%) responded that they had not heard the term. The $10 \%$ who responded that they had heard of "epigenetics" answered that they heard the term from: friends and family, school lectures, internet/ media, or that they did not remember. These results indicate that there is some level of understanding about environmental influences on genetics; however, the vast majority of participants lack knowledge on how geneenvironment interactions might play a role in human health and disease. 
Table 2 Participants perceptions about genetic research and environmental health

\begin{tabular}{lrcc}
\hline Selected responses & Agree $n(\%)$ & $\begin{array}{l}\text { I need to know } \\
\text { more } n(\%)\end{array}$ & Disagree $n(\%)$ \\
\hline Genetic studies are good for society & $165(93 \%)$ & $12(7 \%)$ & 0 \\
Genetic research increases human lifespan & $142(81 \%)$ & $30(17 \%)$ & $4(2 \%)$ \\
Genetic research prevents disease & $154(88 \%)$ & $21(12 \%)$ & $1(<1 \%)$ \\
Genetic research is used to treat disease & $145(82 \%)$ & $30(17 \%)$ & $1(<1 \%)$ \\
Genetic discoveries immediately help people & $46(26 \%)$ & $77(44 \%)$ & $53(30 \%)$ \\
Environmental exposures affect my genes & $131(74 \%)$ & $41(23 \%)$ & $4(2 \%)$ \\
Parental cigarette smoke affects my child's genes & $78(44 \%)$ & $81(46 \%)$ & $17(10 \%)$ \\
Grandparental cigarette smoke affects my child's genes & $52(30 \%)$ & $100(57 \%)$ & $24(14 \%)$ \\
\hline
\end{tabular}

$n=176$

$(90 \%)$ said that they were interested in learning more about

Important factors in making a decision to participate in a genetic research study

To understand the potential barriers in the decisionmaking process of this group of Appalachians, we asked participants to choose potential factors that were either important or not important in their decision to participate in a genetic research study. The top three most important factors selected were: the methods used for sample collection (43\%); whether participation would improve the health of themselves, their children, or future children (43\%); and whether their child's results would be shared with them (28\%) (Table 3$)$. We also asked if there were any other factors not listed that were important in their decision to participate. These "other factors" included: health risks to participants, safety of participants, who would benefit from the study and security of the samples from insurance companies and medical professionals. This result demonstrates the need for clarity in informing these participants as to how their role in the study may lead to the improvement of health in society as well as in their families, describing the methods and security measures involved in collection and storage of a biological sample and whether the results of the study will be shared with them.

Interest in learning more about genetics and useful information in their decision to participate in a genetic research study

To determine if learning about genetics is of significance to this population, we asked about their interest in learning more about the topic. The vast majority of participants genetics (Fig. 1).

In order to determine what information would aid in their decision to participate in a genetic research study (Table 4), we asked the following question: "Given that the field of genetics is rapidly expanding, what information would you find useful, in helping you determine whether or not to participate in a genetic research study?" We found that: $84 \%$ wanted to know more about how pollutants affect genes, $75 \%$ stated that they would like to have more information on the type of biological sample they would need to provide, $74 \%$ would like to know who would have access to their samples, $70 \%$ wanted to know what happens to the samples after the study is completed, $67 \%$ wanted to know more about the health risks involved in providing a sample, $62 \%$ wanted more information on how genes work, and $58 \%$ wanted to know how the samples would be stored. These responses can be categorized into two major themes in what the participants want to know before consenting to a genetic research study: (1) more information on how the environment might affect their genetic make-up and (2) more details on the methods used to collect and maintain security of the genetic sample provided. These results also point to a lack of understanding about basic genetic concepts and genetic research studies, as well as the security of personal information used in a research study.

We also asked if there was other information not listed that would be useful and their responses included: any and all information that could be provided, how the results will be used, speed of results, helpfulness of results to others, safety of participants, heredity of conditions, confidentiality of samples, why the study is being conducted, why the study is important and who will benefit from the study.
Table 3 The leading three most selected factors deemed important in the decision to participate in a genetic research study

${ }^{\mathrm{a}}{ }_{n=168}$

\begin{tabular}{ll}
\hline Top three most important factors & \\
\hline How the genetic material will be collected? & $77(46 \%)$ \\
Will participation improve the health of me, my child, or future children? & $77(46 \%)$ \\
Will my or my child's results be shared with me? & $50(30 \%)$ \\
\hline
\end{tabular}


Fig. 1 Respondent interest in participation in and learning more about genetic research studies. $n=176-177$

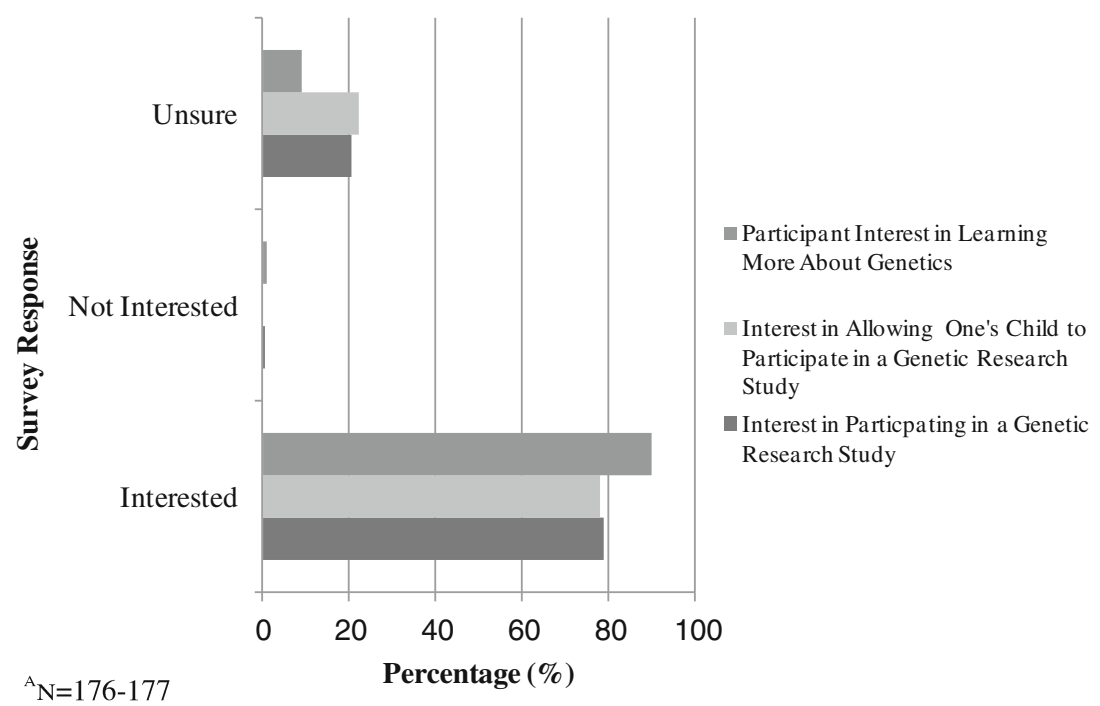

genetic research study, the two main reasons for apprehension were their lack of knowledge about genetic research studies and issues with the security of their genetic information. Other reasons included: type of samples to be provided, how samples will be collected, who is conducting the study, safety of participants, the long-term health effects associated with providing a sample, child willingness, their age and time constraints.

Participants' opinions on the best methods for receiving information or distributing information to the public on genetic research studies

To learn more about how this population would like to receive information on genetic research studies, we asked them to select their preferred method of transmission of this information to them. The choices were: read a brochure, watch a short web video, watch a DVD, talk with a research staff member, or listen to a video recording. Out of 160 respondents, the top three choices were: read a brochure ( $40 \%)$, watch a short web video (16\%), and watch a DVD (16\%). Of note, there was also a relatively high percentage that chose to talk with a research staff member, and this was statistically significant between age groups $(13 \%, p<0.02)$. These data show that most participants would like to receive a source of media that they can read or watch on their own, whereas a smaller but statistically significant percentage of those aged 25-44 would like to speak with a trained research member personally. Suggestions from the participants for this question were: that we should send information to them via postal mail or e-mail. This information will contribute to enhanced education materials for this Appalachian population prior to the consent process.

We also asked them to select the types of communication that would help to improve public knowledge on genetic research studies. The choices were: newspaper articles, TV commercials, community forums, radio programs, or informational

$n=177$ 
Table 5 Reasons for an unsure response to participating in a genetic research study $n=43$

\begin{tabular}{lc}
\hline Selected responses & $n(\%)$ \\
\hline I don’t have enough information about genetic research to make a decision & $24(56 \%)$ \\
My genetic information may not be stored securely & $17(40 \%)$ \\
My genetic information may be made publicly available & $15(35 \%)$ \\
My genetic information may be released to my insurance company & $10(23 \%)$ \\
My genetic information may be released to current or potential employers & $9(21 \%)$ \\
Participating would go against my religious beliefs & $6(14 \%)$ \\
I don't want to give or I don't want my child to give another blood sample & $5(12 \%)$ \\
I may learn that I or my child has a genetic condition that I really don't want to know about & $4(9 \%)$ \\
My spouse or significant other would not approve & $3(7 \%)$ \\
I don't want to give or I don't want my child to give a saliva or cheek swab sample & $1(2 \%)$ \\
\hline
\end{tabular}

brochures. Of 177 respondents, the top three choices were: newspaper articles (57\%), TV commercials (56\%), and brochures $(50 \%)$. Fourteen participants selected 'other' and wrote in suggestions that included: going door-to-door with information, TV programs, more science education in schools, billboards, information from their doctors' office or schools, magazine articles, YouTube videos, text messages, websites and social networking sites such as Facebook.

\section{Limitations}

A limitation of this study is selection bias of the study population. The survey participants had already consented to participate in environmental health research. Therefore, our sample population was already willing to participate in a research study; however, to our knowledge, this was their first experience with a genetic research questionnaire. In addition, our study population had a higher level of educational attainment compared to their respective counties. Educational attainment in our study, however, was slightly lower than reported by the nation according to the US Census Bureau 2010.

\section{Discussion}

To our knowledge, there have been no previously published studies that have identified the thoughts and perceptions of genetics in Appalachian Americans. Our study is also unique in that it: (1) provides the opinions of this population with regard to what information would be helpful when deciding to participate in a genetic research study and the best method for receiving the information, (2) offers insight into this population's knowledge on gene-environment interaction, and (3) addresses the need for tailored environmental genetics communication materials for this population prior to a genetic study. A future genetic research study with this cohort will likely be based on findings from our initial pilot study (Haynes et al. 2010) and by others (Henn et al. 2011), which indicate a potential genetic link between biological manganese concentrations and variants in iron metabolism and zinc transporter genes.

This study adds to the literature base of assessing the perceptions of genetics in at-risk groups. Such previous studies include evaluation of the thoughts and opinions about genetic testing in the Amish, which found that parents of children affected with a genetic disorder were interested in understanding the cause of the health problems and risk of recurrence (Brensinger et al. 1995). Other studies have examined the perceptions and attitudes of genetics, genetic testing, and genomic information of those at high-risk for breast cancer and Alzheimer's disease, women who were offered prenatal testing, African-American and EuropeanAmerican populations, as well as medical professionals, and consumers of genetic services (Lobb et al. 2006; Hiraki et al. 2009; Hines-Martin et al. 2004; Etchegary et al. 2008; O'Daniel et al. 2010; Hernandez et al. 2006). Although thoughts about cancer and vaccines have been addressed in the Appalachian population (Hutson et al. 2007; Hutson et al. 2011; Dorgan et al. 2009; Vanderpool et al. 2010), the topic of genetic research studies has not. Thus, our study fills this void in the literature and adds new information on the Appalachian population.

We found that the vast majority of participants: agreed that genetic research studies benefit society, were interested in themselves and their children participating in a genetic research study, and were eager to learn more about genetics. Despite this, many of the respondents, instead of stating 'no', responded that they were 'unsure' about themselves or their children participating. This disparate response shows a genuine interest for participation, but also may reflect a lack of knowledge about the societal impacts of genetic research. In support of this, we found that when asked what the possible reasons were for an unsure response, the top reason was that they "did not have enough information to make a decision" on participating. This result is also consistent with a recent report that found individuals 
from southern Appalachia often lived in a "sphere of silence". For example, they knew or suspected what human papilloma virus (HPV) was; however, they lacked the knowledge to make the connection between HPV and cervical cancer (Hutson et al. 2011). Together, these findings suggest that it may be critical for researchers working in Appalachian communities to create an educational plan prior to the start of starting a research study.

In addition to understanding their thoughts on genetic research, we also wanted to gauge the level of knowledge about gene-environment interactions. This topic is especially important for this population because most of Appalachia has been infiltrated with industry (Halverson et al. 2004). Many participants affirmed that they thought the environment affects genetics; however, a large number of survey respondents reported that they needed more information about how the environment might affect their genes. For example, many participants stated they needed more information regarding how environmental exposures such as cigarette smoke could affect the genetics of subsequent generations. This was reinforced by the finding that most had never heard the term "epigenetics" and, when asked what topics of genetics they would be interested in learning about, many responded that they wanted to know "how environmental pollutants could affect their genes". Our findings echo a summary of a recent study by Condit et al. (2011) that explored the public understanding of genes and the environment. Using surveys and mathematical relationships of risk, Condit concluded that the perception of how the environment affects genes and the nature of its additive process on health is not easily understood. Given these responses, it is clear that the "gene-environment interaction" concept should be included in future education materials about genetic research studies involving environmental exposures.

To understand more fully, the sample's thoughts and opinions on genetic research, we added the option for respondents to fill in the 'other' category for most of our questions. Open-ended questions invite participants to engage in a research study and is in agreement with Bates et al. (2005) who suggests that the subjects' active participation and interaction in the research study is necessary for future investigations of the public understanding of genetics. These 'other' responses, together with the selection of the choices given on the questionnaire, led to two major overall themes regarding the potential barriers against participation for this population in a genetic research study: (1) the need for more information on genetic research studies, including any risks involved in participation and how participation would be beneficial; and (2) providing more details on the methods used to collect, share and maintain security of the genetic sample. The overarching themes of lack of information and the security of biological samples are suggestive of a level of distrust in this population, regarding the safe handling of their genetic information. Although we have an established relationship with these communities, the apprehension towards security of the biological sample could be a potential barrier against participation in future genetic research studies. This problem further underscores the importance of establishing trust within Appalachian communities (Behringer et al. 2006). Similarly, it has been reported that many Appalachians are suspicious of medical industries such as drug companies (Hutson et al. 2011) and that distrust in medical research and researchers is a key factor in minority groups' decreased willingness to participate in research studies (Braunstein et al. 2008; Corbie-Smith et al. 1999).

Seeking the opinions of research study participants on the best modes of communication for the topic of genetics for both themselves and society, we asked them to select or provide their preferred method. While most participants' responses were to read a brochure, watch a web video or DVD, a smaller percentage stated that they would like to speak with a trained research staff member. This finding was statistically significant across age groups perhaps, indicating a stronger level of distrust among the younger participants. Additional write-in responses for better modes of communication with the public about genetics included the use of new media sources like text messaging, YouTube, and Facebook. The number and type of responses we received highlight the need for more tailored and updated educational materials for communicating with potential research subjects and the general public.

Both the Institute of Medicine and the American Academy for the Advancement of Science (AAAS) have called for enhanced communication among scientists and the public (AAAS 2012). Preliminary data-gathering, such as this questionnaire, becomes a necessary and essential step in preparing communication messages, and supports previous research (Resnicow et al. 2008) that embraces the challenges of complex public health problems by approaching them from a multilevel perspective. By approaching the issue from a scientific (what do participants need to know about genetics and epigenetics?) and from a communication perspective (what is the best way to deliver this information?), we are better positioned to conduct future genetic research studies and avoid the much discussed difficulties of scientists communicating with the public (Mathews et al. 2005; Davies et al. 2008; Watkins et al. 2009). Our study helps to bridge this communication gap in that we encouraged the potential participants of a genetic research study to play an active role in describing what information they would need before consenting, what factors play a role in their decision on whether or not to participate and how we as scientists can better serve their community in providing relevant information on genetics. Furthermore, our findings show that, although the majority of the survey respondents 
were interested in participating in a genetic study, there were still some who are uncertain about participation and who have a lack of knowledge about genetic research studies overall. Therefore, the thoughts and perceptions of topics such as genetics should be considered-when designing recruiting methods and consent materials, aimed at conducting genetic research studies with under-represented or at-risk populations.

Conflict of interest The authors declare they have no conflict of interest.

\section{References}

American Academy for the Advancement of Science (AAAS). Available at http://www.aaas.org/aboutaaas/. Accessed 15 March 2012

Appalachian Regional Commission. (2008). The Appalachian region. Retrieved from http:/www.arc.gov/appalachian region/ TheAppalachianRegion.asp. Accessed July 16, 2012

Barnett E, Williams CR, Moore L, Chen F (2002) Social class and heart disease mortality among African Americans. Ethn Dis 12 (4):S3,76-81

Bates BR (2005) Public culture and public understanding of genetics: a focus group study. Public Underst Sci 14(1):47-65

Behringer B, Friedell GH (2006) Appalachia: where place matters in health. Prev Chronic Dis 3(4):A113

Bick D, Dimmock D (2011) Whole exome and whole genome sequencing. Curr Opin Pediatr 23(6):594-600

Braunstein JB, Sherber NS, Schulman SP, Ding EL, Powe NR (2008) Race, medical researcher distrust, perceived harm, and willingness to participate in cardiovascular prevention trials. Medicine (Baltimore) 87(1):1-9

Brensinger JD, Renata L (1995) The Amish: perceptions of genetic disorders and services. J Genet Couns 4(1):27

Center for Clinical and Translational Science and Training (CCTST) at the University of Cincinnati. Available at http://cctst.uc.edu/node/ 58. Accessed 15 March 2012

Center for Disease Control Data and Statistics (CDC). Available at http://www.cdc.gov/DataStatistics/. Accessed 15 March 2012

Center for Disease Control Data and Statistics (CDC). Available at http:// www.cdc.gov/obesity/data/trends.html. Accessed 15 March 2012

Condit CM, Shen L (2011) Public understanding of risks from geneenvironment interaction in common diseases: implications for public communications. Public Health Genomics 14(2):115-24

Corbie-Smith G, Thomas SB, Williams MV, Moody-Ayers S (1999) Attitudes and beliefs of African Americans toward participation in medical research. J Gen Intern Med 14(9):537-46

Davies S (2008) Constructing communication: talking to scientists about talking to the public. J Sci Commun 29(4):413

Dorgan KA, Hutson SP, Gerding G, Duvall KL (2009) Culturally tailored cancer communication, education, and research: the highways and back roads of Appalachia. Prev Chronic Dis 6(2):A68

Elnicki DM, Morris DK, Shockcor WT (1995) Patient-perceived barriers to preventive health care among indigent, rural Appalachian patients. Arch Intern Med 155(4):421-4

Etchegary H, Potter B, Howley H, Cappelli M, Coyle D, Graham I et al (2008) The influence of experiential knowledge on prenatal screening and testing decisions. Genet Test 12(1):115-24

Friedell GH, Linville LH, Rubio A, Wagner WD, Tucker TC (1997) What providers should know about community cancer control. Cancer Pract 5(6):367-74
Halverson JA, Barnett E, Casper M (2002) Geographic disparities in heart disease and stroke mortality among black and white populations in the Appalachian region. Ethn Dis 12(4):S3,82-91

Halverson JA, Ma L, Harner EJ (2004) An analysis of disparities in health status and access to health care in the Appalachian region. Appalachian Regional Commission, Washington DC

Haynes EN, Heckel P, Ryan P, Roda S, Leung YK, Sebastian K et al (2010) Environmental manganese exposure in residents living near a ferromanganese refinery in southeast Ohio: a pilot study. Neurotoxicology 31(5):468-74

Haynes EN, Beidler C, Wittberg R, Meloncon L, Parin M, Kopras EJ et al (2011) Developing a bidirectional academic-community partnership with an Appalachian-American community for environmental health research and risk communication. Environ Health Perspect 119(10): 1364-72

Haynes EN, Ryan P, Chen A, Brown D, Roda S, Kuhnell P, Terrell M, Reponen T. Assessment of personal exposure to manganese in children living near a ferromanganese refinery. Sci Total Environ. 2012. Published online April 30

Hendryx M, Zullig KJ (2009) Higher coronary heart disease and heart attack morbidity in Appalachian coal mining regions. Prev Med 49(5):355-9

Henn BC, Kim J, Wessling-Resnick M, Tellez-Rojo MM, Jayawardene I, Ettinger AS et al (2011) Associations of iron metabolism genes with blood manganese levels: a population-based study with validation data from animal models. Environ Health 10:97

Hernandez VR, Selber K, Tijerina MS (2006) Visioning familycentered care in genetics: what parents and providers have to say. J Genet Couns 15(5):349-60

Hines-Martin VP, Usui W, Kim S, Furr A (2004) A comparison of influences on attitudes towards mental health service use in an African-American and white community. J Natl Black Nurses Assoc 15(2):17-22

Hiraki S, Chen CA, Roberts JS, Cupples LA, Green RC (2009) Perceptions of familial risk in those seeking a genetic risk assessment for Alzheimer's disease. J Genet Couns 18(2):130-6

Hurley JL, Turner HS, Floyd DL (2000) Development of a health service at a rural community college in Appalachia. J Am Coll Health 48(4):181-5

Hutson SP, Dorgan KA, Phillips AN, Behringer B (2007) The mountains hold things in: the use of community research review work groups to address cancer disparities in Appalachia. Oncol Nurs Forum 34(6):1133-9

Hutson SP, Dorgan KA, Duvall KL, Garrett LH (2011) Human papillomavirus infection, vaccination, and cervical cancer communication: the protection dilemma faced by women in southern Appalachia. Women Health 51(8):795-810

Lanie AD, Jayaratne TE, Sheldon JP, Kardia SL, Anderson ES, Feldbaum $M$ et al (2004) Exploring the public understanding of basic genetic concepts. J Genet Couns 13(4):305-20

Lobb EA, Butow PN, Moore A, Barratt A, Tucker K, Gaff C et al (2006) Development of a communication aid to facilitate risk communication in consultations with unaffected women from high risk breast cancer families: a pilot study. J Genet Couns 15(5):393-405

Mathews DJ, Kalfoglou A, Hudson K (2005) Geneticists' views on science policy formation and public outreach. Am J Med Genet A 137(2):161-9

Murray CJ, Kulkarni S, Ezzati M (2005) Eight Americas: new perspectives on U.S. health disparities. Am J Prev Med 29(5 Suppl 1):4-10

O'Daniel JM, Haga SB, Willard HF (2010) Considerations for the impact of personal genome information: a study of genomic profiling among genetics and genomics professionals. J Genet Couns 19(4):387-401

Resnicow K, Page SE (2008) Embracing chaos and complexity: a quantum change for public health. Am J Public Health 98 (8):1382-9 
Samuel GN, Jordens CF, Kerridge I (2010) Direct-to-consumer personal genome testing: ethical and regulatory issues that arise from wanting to 'know' your DNA. Intern Med J 40 (3): $220-4$

Standridge JS, Bhattacharya A, Succop P, Cox C, Haynes E (2008) Effect of chronic low level manganese exposure on postural balance: a pilot study of residents in southern Ohio. J Occup Environ Med 50(12):1421-9

Steenland K, Tinker S, Frisbee S, Ducatman A, Vaccarino V (2009) Association of perfluorooctanoic acid and perfluorooctane sulfonate with serum lipids among adults living near a chemical plant. Am J Epidemiol 170(10):1268-78

Suhre K, Shin SY, Petersen AK, Mohney RP, Meredith D, Wagele B et al (2011) Human metabolic individuality in biomedical and pharmaceutical research. Nature 477(7362):54-60
United States Census Bureau. 2010

Vanderpool RC, Huang B (2010) Cancer risk perceptions, beliefs, and physician avoidance in Appalachia: results from the 2008 HINTS survey. J Health Commun 15(Suppl 3):78-91

von Bubnoff A (2008) Next-generation sequencing: the race is on. Cell 132(5):721-3

Watkins BX, Shepard PM, Corbin-Mark CD (2009) Completing the circle: a model for effective community review of environmental health research. Am J Public Health 99(Suppl 3):S567-77

Wewers ME, Ahijevych KL, Chen MS, Dresbach S, Kihm KE, Kuun PA (2000) Tobacco use characteristics among rural Ohio Appalachians. J Community Health 25(5):377-88

Wingo PA, Howe HL, Thun MJ, Ballard-Barbash R, Ward E, Brown ML et al (2005) A national framework for cancer surveillance in the United States. Cancer Causes Control 16(2):151-70 